Check for updates

Cite this: RSC Adv., 2017, 7, 32310

Received 19th April 2017 Accepted 19th June 2017

DOI: $10.1039 / \mathrm{c} 7 \mathrm{ra0} 4390 \mathrm{~b}$

rsc.li/rsc-advances

\section{Pd-Ni nanoparticles supported on reduced graphene oxides as catalysts for hydrogen generation from hydrazine $\uparrow$}

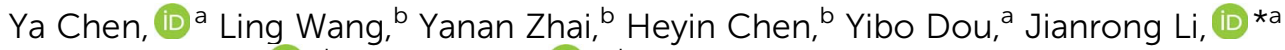 \\ Haoquan Zheng (iD *b and Rui Cao (iD *ab
}

\begin{abstract}
A composite material of $\mathrm{Pd}-\mathrm{Ni}$ nanoparticles supported on reduced graphene oxide $(\mathrm{Pd}-\mathrm{Ni} / \mathrm{rGO}$ ) has been synthesised via an in situ reduction of $\mathrm{PdO} / \mathrm{Ni}(\mathrm{OH})_{2}$ nanoparticles on $\mathrm{GO}$. This $\mathrm{Pd}-\mathrm{Ni} / \mathrm{rGO}$ material is characterised by powder $\mathrm{X}$-ray diffraction, transmission electron microscopy, scanning electron microscopy and X-ray photoelectron spectroscopy. The molar ratio of $\mathrm{Pd} / \mathrm{Ni}$ in the alloy nanoparticles can be fine tuned by changing the starting ratio of $\mathrm{Pd} / \mathrm{Ni}$ precursors during synthesis. The bimetallic $\mathrm{Pd}_{3} \mathrm{Ni} / \mathrm{rGO}$ exhibits high catalytic activity, selectivity, and durability toward the hydrogen generation from hydrazine, while corresponding monometallic ( $\mathrm{Pd} / \mathrm{rGO}$ or $\mathrm{Ni} / \mathrm{rGO}$ ) counterparts are either inactive or poorly active under analogous reaction conditions.
\end{abstract}

\section{Introduction}

Hydrogen is a globally accepted clean fuel due to its high efficiency and power density. ${ }^{\mathbf{1 - 3}}$ High hydrogen content (8.0 wt\%) and easy recharging make hydrazine a promising hydrogen carrier. $^{4-6}$ Furthermore, hydrazine is a liquid-phase material, which has the potential to take the advantage of the existing liquid-based distribution infrastructure. Transition metals are usually considered as the ideal candidates for hydrogen generation from hydrazine. ${ }^{7-13}$ However, monometallic catalysts are either inactive or poorly active in this reaction..$^{\mathbf{4 1 4 1 5}}$ In comparison, bimetallic materials, especially Ni-based bimetallic materials, are of great importance for the electrochemical production of hydrogen from hydrazine due to the synergetic effect from the inter-metallic combinations of different metals. ${ }^{16-28}$ These bimetallic systems exhibit fast reaction kinetics and high selectivity toward hydrogen generation.

Ultra-small metal nanocatalysts $(<7 \mathrm{~nm})$ have received substantial attention, because they show high catalytic efficiencies in numerous reactions. ${ }^{29-33}$ However, the broad particle size distribution and the aggregation of metal NPs during reaction limit their applications. Supports can be used to solve

${ }^{a}$ Beijing Key Laboratory for Green Catalysis and Separation, Department of Chemistry and Chemical Engineering, College of Environmental and Energy Engineering, Beijing University of Technology, Beijing 100124, P. R. China. E-mail: ruicao@ruc.edu.cn; jrli@bjut.edu.cn

${ }^{b}$ Key Laboratory of Applied Surface and Colloid Chemistry, Ministry of Education, School of Chemistry and Chemical Engineering, Shaanxi Normal University, Xi'an 710119, China. E-mail: zhenghaoquan@snnu.edu.cn

$\dagger$ Electronic supplementary information (ESI) available: XRD patterns and EDX of $\mathrm{Pd}_{3} \mathrm{Ni} / \mathrm{rGO}$, photographs of $\mathrm{Na}_{2} \mathrm{PdCl}_{4}, \mathrm{PdO} \cdot \mathrm{H}_{2} \mathrm{O}, \mathrm{NiCl}_{2}$ and $\mathrm{Ni}(\mathrm{OH})_{2}$ and durability test of $\mathrm{Pd}_{3} \mathrm{Ni} / \mathrm{rGO}$ after different cycles. See DOI: $10.1039 / \mathrm{c} 7 \mathrm{ra04390b}$ this problem. ${ }^{34}$ Among all the supports, the reduced graphene oxide (rGO) is an ideal one because of its large surface area, good electrical conductivity, and excellent mechanical strength. ${ }^{35-37}$

Metal NPs/rGO composite materials have been synthesised and used as nanocatalysts. Impregnation and coprecipitation are current manufacturing methods to introduce metal NPs on rGO, where metal salts were first adsorbed on rGO and then reduced by $\mathrm{NaBH}_{4}$. The obtained metal NPs have a broad size distribution from a few nanometers to micrometers. Although the use of surfactant can narrow the size distribution, the catalytic activity decreases unfortunately. ${ }^{38-40}$ Recently, an in situ reduction approach has been developed. ${ }^{\mathbf{4 1 - 4 3}}$ Instead of loading metal ions on rGO, metal oxide NPs with a narrow particle size distribution were loaded onto graphene oxide (GO). Metal oxide NPs and GO were then reduced to metal NPs and rGO, respectively, by $\mathrm{NaBH}_{4}$ in one pot. Here, we synthesise a composite material of $\mathrm{Pd}-\mathrm{Ni}$ bimetallic NPs supported on reduced graphene oxide $(\mathrm{Pd}-\mathrm{Ni} / \mathrm{rGO})$ via an in situ reduction of $\mathrm{PdO} /$ $\mathrm{Ni}(\mathrm{OH})_{2}$ NPs on GO. This novel catalytic system was found to display efficient activity and high selectivity for dehydrogenation of alkaline solution of hydrazine.

\section{Experimental section}

\subsection{Chemicals}

Graphene oxide (GO) was purchased from Nanjing XFNANO Materials TECH Co., Ltd. The following reagents were purchased from Sinopharm Chemical Reagent Co., Ltd. and used without purification: $\mathrm{PdCl}_{2}, \mathrm{NiCl}_{2}, \mathrm{NaBH}_{4}$, and $\mathrm{NaOH}$. 


\subsection{Synthesis of materials}

Synthesis of the $\mathrm{Pd} / \mathrm{rGO}$ composites and $\mathrm{Ni} / \mathrm{rGO}$ composites. In a typical procedure, $1.21 \mathrm{~mL}$ of $0.1 \mathrm{M} \mathrm{H}_{2} \mathrm{PdCl}_{4}$ solution was added into an as-prepared $10 \mathrm{~mL} 3 \mathrm{mg} \mathrm{mL}^{-1}$ of GO suspension and stirred for $10 \mathrm{~min}$. After adjusting the $\mathrm{pH}$ of the mixture to 6.5 , the suspension was heated at $40{ }^{\circ} \mathrm{C}$ for $6 \mathrm{~h}$. Then, $6 \mathrm{~mL} 1 \mathrm{M}$ $\mathrm{NaBH}_{4}$ of solution was added into the suspension and stirred for $60 \mathrm{~min}$. After the reaction, the obtained $\mathrm{Pd} / \mathrm{rGO}$ composites were separated by centrifugation at $6000 \mathrm{rpm}$, and then dried at $50{ }^{\circ} \mathrm{C}$ for $12 \mathrm{~h}$ in a vacuum dryer.

The same process was used as that used for the Ni/rGO composites, with the $1.21 \mathrm{~mL}$ of $0.1 \mathrm{M} \mathrm{H}_{2} \mathrm{PdCl}_{4}$ solution replaced by $2.18 \mathrm{~mL}$ of $0.1 \mathrm{M} \mathrm{NiCl}_{2}$ solution.

Synthesis of the $\mathrm{Pd}_{3} \mathrm{Ni} / \mathrm{rGO}$ composites. In a typical procedure, $1.023 \mathrm{~mL}$ of $0.1 \mathrm{M} \mathrm{H}_{2} \mathrm{PdCl}_{4}$ and $0.341 \mathrm{~mL}$ of $0.1 \mathrm{M} \mathrm{NiCl}_{2}$ solution was added into an as-prepared $10 \mathrm{~mL} 3 \mathrm{mg} \mathrm{mL}^{-1}$ of GO suspension and stirred for $10 \mathrm{~min}$. After adjusting the $\mathrm{pH}$ of the mixture to 8 , the suspension was heated at $40{ }^{\circ} \mathrm{C}$ for $6 \mathrm{~h}$. A solution of $7 \mathrm{~mL} 1 \mathrm{M} \mathrm{NaBH}_{4}$ was added into the suspension and stirred for $60 \mathrm{~min}$. After the reaction, the obtained $\mathrm{Pd}_{3} \mathrm{Ni} / \mathrm{rGO}$ composites were separated by centrifugation at $6000 \mathrm{rpm}$, and then dried at $50{ }^{\circ} \mathrm{C}$ for $12 \mathrm{~h}$ in a vacuum dryer. The preparation of the $\mathrm{PdNi} / \mathrm{rGO}$ and $\mathrm{PdNi}_{3} / \mathrm{rGO}$ is following the analogous process. For PdNi/rGO composites, $0.78 \mathrm{~mL}$ of $0.1 \mathrm{M} \mathrm{H}_{2} \mathrm{PdCl}_{4}$, $0.78 \mathrm{~mL}$ of $0.1 \mathrm{M} \mathrm{NiCl}_{2}$ and $8 \mathrm{~mL} 1 \mathrm{M} \mathrm{NaBH}_{4}$ were used, while $0.454 \mathrm{~mL}$ of $0.1 \mathrm{M} \mathrm{H}_{2} \mathrm{PdCl}_{4}, 1.362 \mathrm{~mL}$ of $0.1 \mathrm{M} \mathrm{NiCl}_{2}$ and $9 \mathrm{~mL}$ $1 \mathrm{M} \mathrm{NaBH}_{4}$ were used to synthesise $\mathrm{PdNi}_{3} / \mathrm{rGO}$.

\subsection{Catalytic activities}

Catalytic reactions were carried out using a two-necked round bottom flask which contained the as prepared nanocatalysts (20 $\mathrm{mg}$ ). One neck of the flask was connected to a gas burette and the other was connected to a pressure-equalization funnel to introduce $18 \mathrm{~mL} \mathrm{NaOH}(0.5 \mathrm{M})$. The suspension was stirred for
$30 \mathrm{~min}$, and then $2 \mathrm{~mL}$ of solution containing $\mathrm{N}_{2} \mathrm{H}_{4} \cdot \mathrm{H}_{2} \mathrm{O}(0.5 \mathrm{M})$ was added. The catalytic reaction was begun once the hydrazine aqueous solution was added into the catalyst suspension in the flask with magnetic stirring at $323 \mathrm{~K}$. The evolution of gas was monitored using the gas burette. The selectivity toward $\mathrm{H}_{2}$ generation can be calculated using equation: $X=(3 \lambda-1) / 8[\lambda=$ $\left.n\left(\mathrm{H}_{2}+\mathrm{N}_{2}\right) / n\left(\mathrm{H}_{2} \mathrm{NNH}_{2}\right)\right]$.

The reactions over $\mathrm{Pd}_{3} \mathrm{Ni} / \mathrm{rGO}$ composites were carried out at different temperatures (303, 313, 323, 333 and $343 \mathrm{~K})$ to evaluate their activation energies for the decomposition of hydrazine in aqueous solution under ambient atmosphere.

\section{Results and discussions}

As shown in Fig. 1, GO that has $-\mathrm{OH}$ and $-\mathrm{COOH}$ groups without any further functionalisation was directly purchased and used as supports. A stock solution of $\mathrm{H}_{2} \mathrm{PdCl}_{4}$ and $\mathrm{NiCl}_{2}$ was prepared. Then, the stock solution and GO were mixed. The $\mathrm{pH}$ of the solution was adjusted to 8 by $\mathrm{NaOH}$, so that $\mathrm{PdO} / \mathrm{Ni}(\mathrm{OH})_{2}$ nanoparticles were loaded onto GO due to the strong interaction between them and functional groups on GO. The suspension was then reduced by $\mathrm{NaBH}_{4}$. The molar ratios of $\mathrm{Pd}$ and $\mathrm{Ni}$ in $\mathrm{Pd}-\mathrm{Ni} / \mathrm{rGO}$ hybrid materials can be tuned by changing the $\mathrm{H}_{2} \mathrm{PdCl}_{4} / \mathrm{NiCl}_{2}$ ratio in the stock solutions. The bimetallic systems were denoted as $\mathrm{Pd}_{3} \mathrm{Ni} / \mathrm{rGO}, \mathrm{PdNi} / \mathrm{rGO}$ and $\mathrm{PdNi}_{3} / \mathrm{rGO}$ with the $\mathrm{Pd}$ : Ni molar ratio of $3: 1,1: 1$ and $1: 3$, respectively. The monometallic systems were denoted as $\mathrm{Pd} / \mathrm{rGO}$ and $\mathrm{Ni} / \mathrm{rGO}$, respectively.

Fig. 2 shows the powder X-ray diffraction (PXRD) patterns of $\mathrm{Pd}-\mathrm{Ni} / \mathrm{rGO}$ hybrid materials. There is no diffraction peak at $10.3^{\circ}$, corresponding to the (001) reflection of graphene oxide, which demonstrates the full reduction of GO. The diffraction peaks of $\mathrm{Pd} / \mathrm{rGO}$ at $40.1,46.1,67.4$, and $81.5^{\circ}$ correspond to (111), (200), (220) and (311) facets of face centred cubic (fcc) crystal structured Pd NPs (Fig. 2, red bar, JCPDS 5-681), while

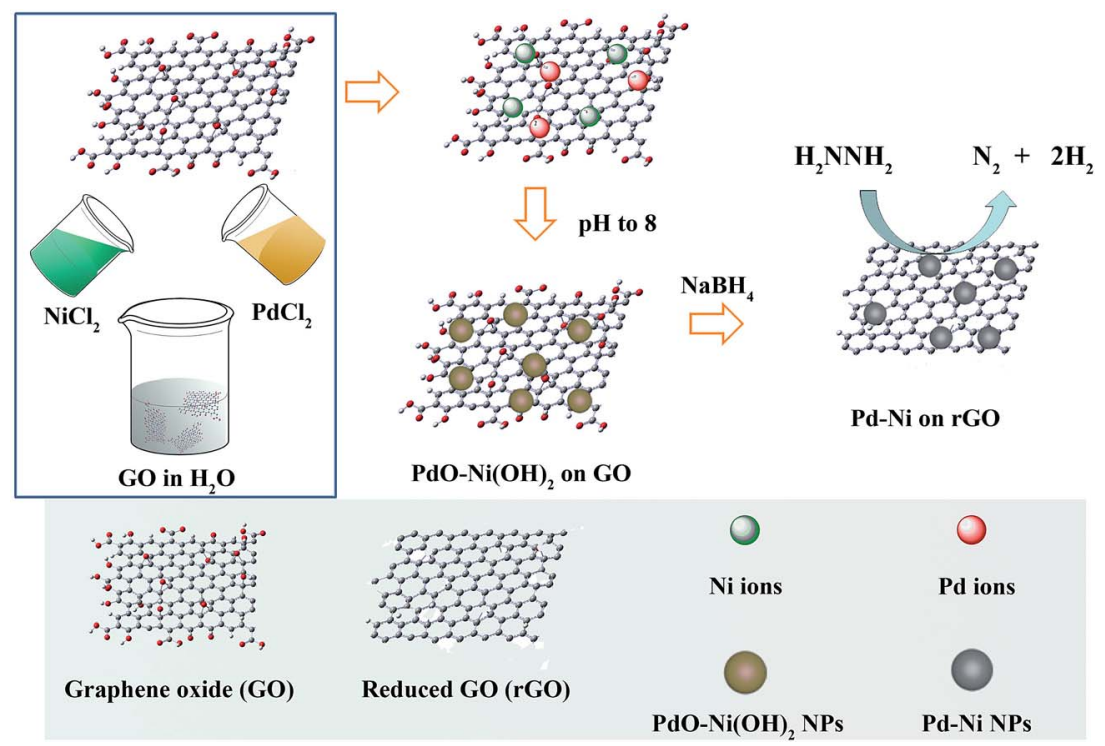

Fig. 1 Schematic illustration for the synthesis of $\mathrm{Pd}-\mathrm{Ni} / \mathrm{rGO}$ catalysts. 


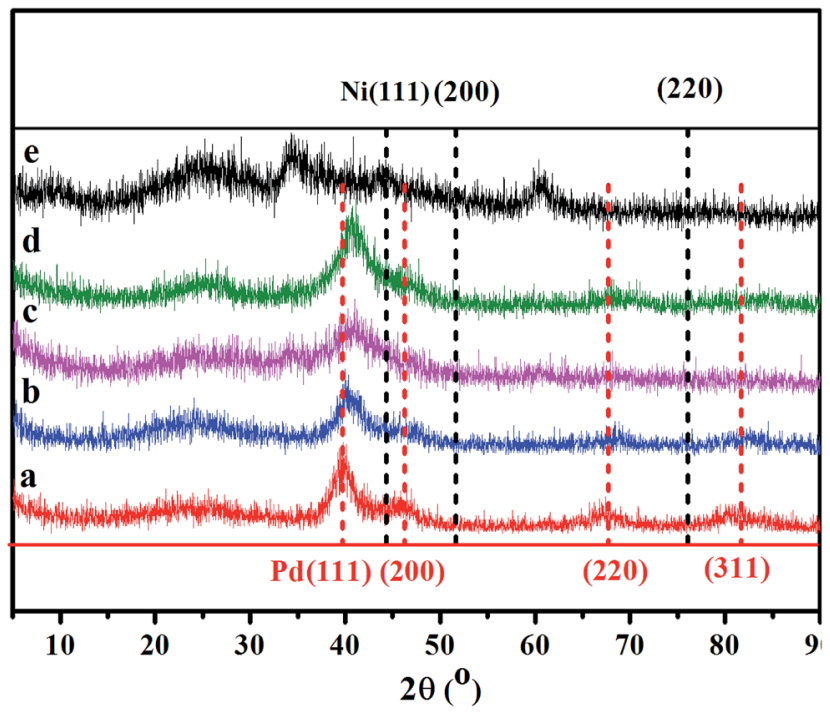

Fig. 2 PXRD patterns of $\mathrm{Pd} / \mathrm{rGO}$ (a), $\mathrm{Pd}_{3} \mathrm{Ni} / \mathrm{rGO}$ (b), PdNi/rGO (c), $\mathrm{PdNi}_{3} / \mathrm{rGO}(\mathrm{d})$ and $\mathrm{Ni} / \mathrm{rGO}(\mathrm{e})$.

the peaks of $\mathrm{Ni} / \mathrm{rGO}$ at $44.8,52.0$ and $76.6^{\circ}$ are assigned to the (111), (200), and (220) facets of Ni NPs. For Ni/rGO, the peaks of $\mathrm{NiO}$ can also be observed. Compared with the monometallic systems, no individual peak of pure Ni or Pd NPs was observed in the PXRD profiles of $\mathrm{Pd}-\mathrm{Ni} / \mathrm{rGO}$. The representative diffraction peaks of $\mathrm{Pd}-\mathrm{Ni} / \mathrm{rGO}$ are coincidently located between peaks of $\mathrm{Pd} / \mathrm{rGO}$ and those of $\mathrm{Ni} / \mathrm{rGO}$ (Fig. 2), demonstrating that the partial Ni has entered into the Pd lattice and an alloy of Pd-Ni was formed. The crystal size of $\mathrm{Pd}-\mathrm{Ni} / \mathrm{rGO}$ is estimated to be $5 \mathrm{~nm}$ according to the Scherrer formula. ${ }^{\mathbf{4 4}}$
The adjustment of $\mathrm{pH}$ by a solution of $\mathrm{NaOH}$ before reduction is important for the formation of Pd-Ni alloy NPs. In principle, $\mathrm{Pd}$ and $\mathrm{Ni}$ are miscible and can form alloy all over the phase diagram with fcc structures. ${ }^{45}$ However, if the $\mathrm{pH}$ was not adjusted, the PXRD pattern of the $\mathrm{Pd}-\mathrm{Ni} / \mathrm{rGO}$ is a combined crystalline feature of $\mathrm{Pd}$ and $\mathrm{Ni}$, indicating the coexistence of these components (Fig. S1†).

The morphology and surface structure of $\mathrm{Pd}_{3} \mathrm{Ni} / \mathrm{rGO}$, that shows the highest activity in hydrogen generation from hydrazine (see results in catalytic reaction), were further investigated by scanning electron microscopy (SEM), transmission electron microscopy (TEM) and X-ray photoelectron spectroscopy (XPS) (Fig. 3). The TEM image shows a $2 \mathrm{D}$ nanosheet, which is the typical morphology of rGO (Fig. 3a). No big particle on nanosheet was observed, suggesting the homogenous distribution of $\mathrm{Pd}_{3} \mathrm{Ni}$ NPs on the rGO. Fig. 3b shows the SEM image and the energy-dispersive X-ray spectroscopy (EDS) mapping of the same area. Both Pd and Ni elements were distributed in a welldispersed pattern throughout the whole area. The atomic ratio of $\mathrm{Pd} / \mathrm{Ni}$ is 2.71 , which is consistent with the expected composition of $\mathrm{Pd}_{3} \mathrm{Ni}$ (Fig. S2 $\dagger$ ). The XPS of $\mathrm{Pd}_{3} \mathrm{Ni} / \mathrm{rGO}$ exhibits characteristic signals for $\mathrm{Pd}^{0}$ and $\mathrm{Ni}^{0}$, indicating the coexistence of both metals (Fig. 3c and d). ${ }^{9}$ The binding energies in the $\operatorname{Pd}\left[3 \mathrm{~d}_{5 /}\right.$ 2] for the bimetallic $\mathrm{Pd}_{3} \mathrm{Ni} / \mathrm{rGO}$ nanocatalysts shifted to higher value demonstrating the alloy formation. ${ }^{16}$ The percentage of $\mathrm{Pd}^{0}$ and $\mathrm{Ni}^{0}$ species in $\mathrm{Pd}_{3} \mathrm{Ni} / \mathrm{rGO}$ composites is calculated to be 82.35 and $76.21 \%$, respectively. The oxidized $\mathrm{Pd}$ and Ni species in XPS may be formed during the sample preparation.

The spherical $\mathrm{Pd}_{3} \mathrm{Ni}$ NPs are well-dispersed on the $\mathrm{rGO}$ (Fig. 4a). The size distribution of $\mathrm{Pd}_{3} \mathrm{Ni}$ NPs on the rGO surface was measured from TEM images, showing a high uniformity $\mathbf{a}$

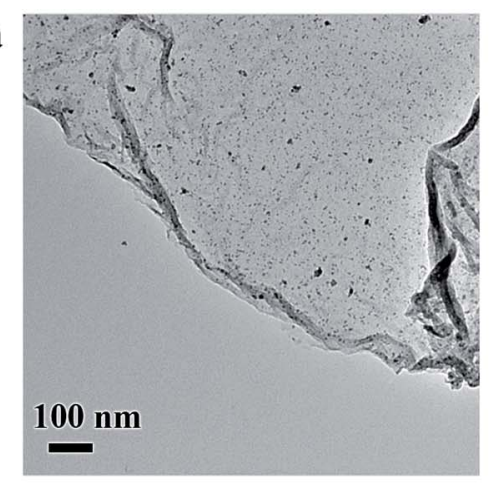

c

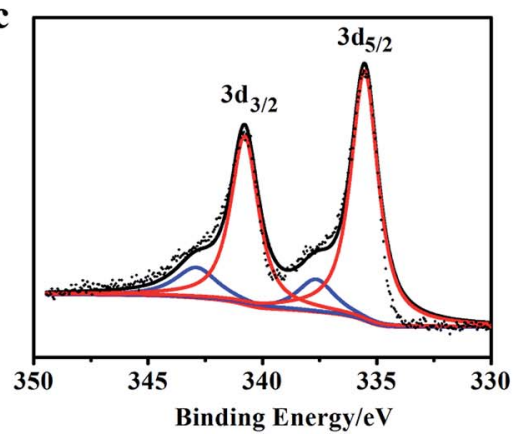

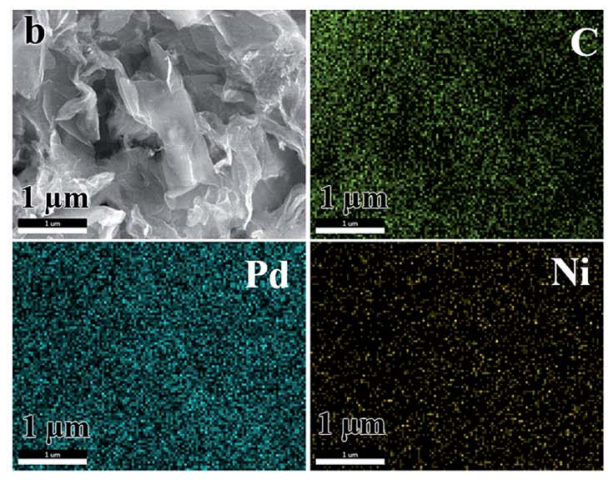

d

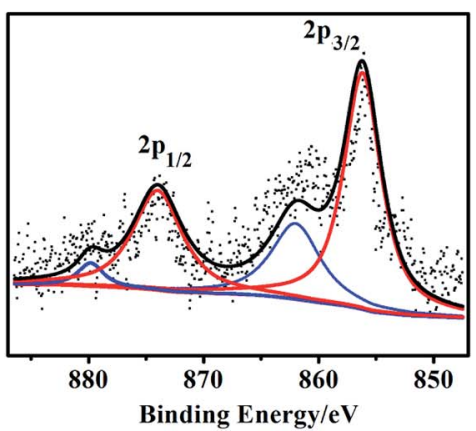

Fig. 3 TEM image (a), SEM image and corresponding EDS mapping (b), and XPS spectra (c and d) of Pd and Ni of Pd 3 Ni/rGO catalyst, respectively. 


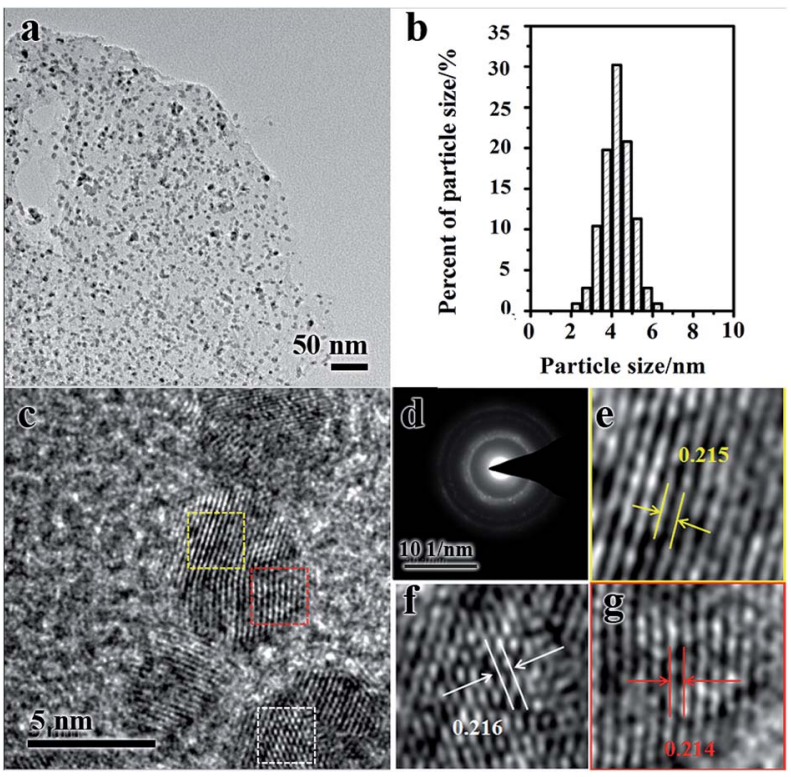

Fig. 4 TEM image (a), the average diameter and distribution (b), high resolution TEM image (c) and SAED (d) of $\mathrm{Pd}_{3} \mathrm{Ni} / \mathrm{rGO}$ catalyst. (e, $\mathrm{f}$ and g) Enlarged image of three areas in (c).

with an average diameter of 4.3 and a standard deviation of $c a$. $16 \%$ (Fig. 4b). The metal NPs in metal NPs/rGO composites have similar particle sizes as the original metal oxide NPs have
(Fig. S3†). High resolution TEM (HRTEM) image shows wellresolved lattice fringes in $\mathrm{Pd}_{3} \mathrm{Ni} \mathrm{NPs}$ (Fig. 4c). The selected area electron diffraction (SAED) of $\mathrm{Pd}_{3} \mathrm{Ni}$ NPs on rGO gives a ring-like pattern (Fig. 4d), which suggests a random orientation of the $\mathrm{Pd}_{3} \mathrm{Ni}$ nanocrystals. The clear lattice fringes with an average value of $0.214 \mathrm{~nm}$ can demonstrate the crystalline nature of fcc $\mathrm{Pd}_{3} \mathrm{Ni}$ alloy, which is between the Pd (111) crystal plane $(0.224 \mathrm{~nm})$ and the $\mathrm{Ni}(111)$ plane $(0.203 \mathrm{~nm})$ (Fig. 4e-g). The loading of $\mathrm{Pd}_{3} \mathrm{Ni}$ is $34.19 \mathrm{wt} \%$. It is worth emphasizing that the control of particle size of metal NPs with high loading $(>30$ wt $\%)$ is quite challenging. High loadings of metal NPs may induce the aggregation of NPs. In this work, the hybrid metal oxide NPs of $\mathrm{PdO} / \mathrm{Ni}(\mathrm{OH})_{2}$ on $\mathrm{GO}$ were synthesised as precursors. The particle size of metal oxides was easy to control. Then, the in situ reduction approach were used. The particle size of NPs on GO does not change during the reduction. The in situ reduction approach shows advantages in the control of particle size compared to the post-reduction procedure.

To investigate the dependence of activity and hydrogen selectivity on the $\mathrm{Pd} / \mathrm{Ni}$ ratio, the $\mathrm{Pd}-\mathrm{Ni} / \mathrm{rGO}$ materials have been tested for the catalytic dehydrogenation of aqueous solution of hydrazine at $50{ }^{\circ} \mathrm{C}$ in the presence of $0.5 \mathrm{M} \mathrm{NaOH}$ (Fig. 5a). For all Pd-Ni/rGO nanocatalysts, an initiation release of gas can be observed as soon as the hydrazine was added. The amount of resulting gas was used to evaluate the selectivity towards hydrogen in this reaction. The activities of the catalysts were strongly dependent on the composition of Pd-Ni NPs,

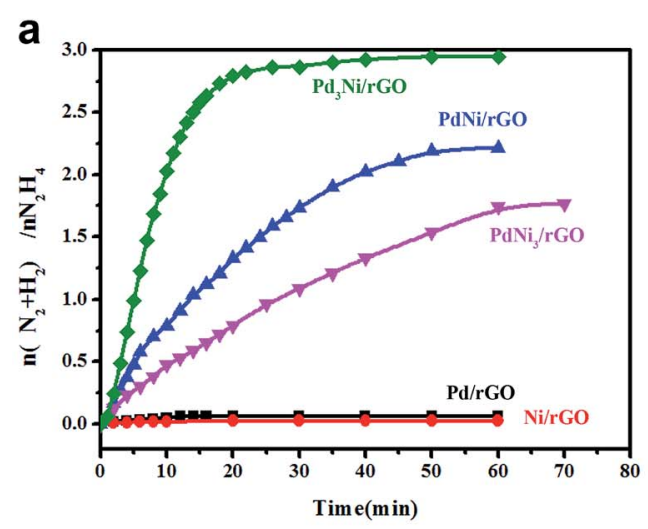

b
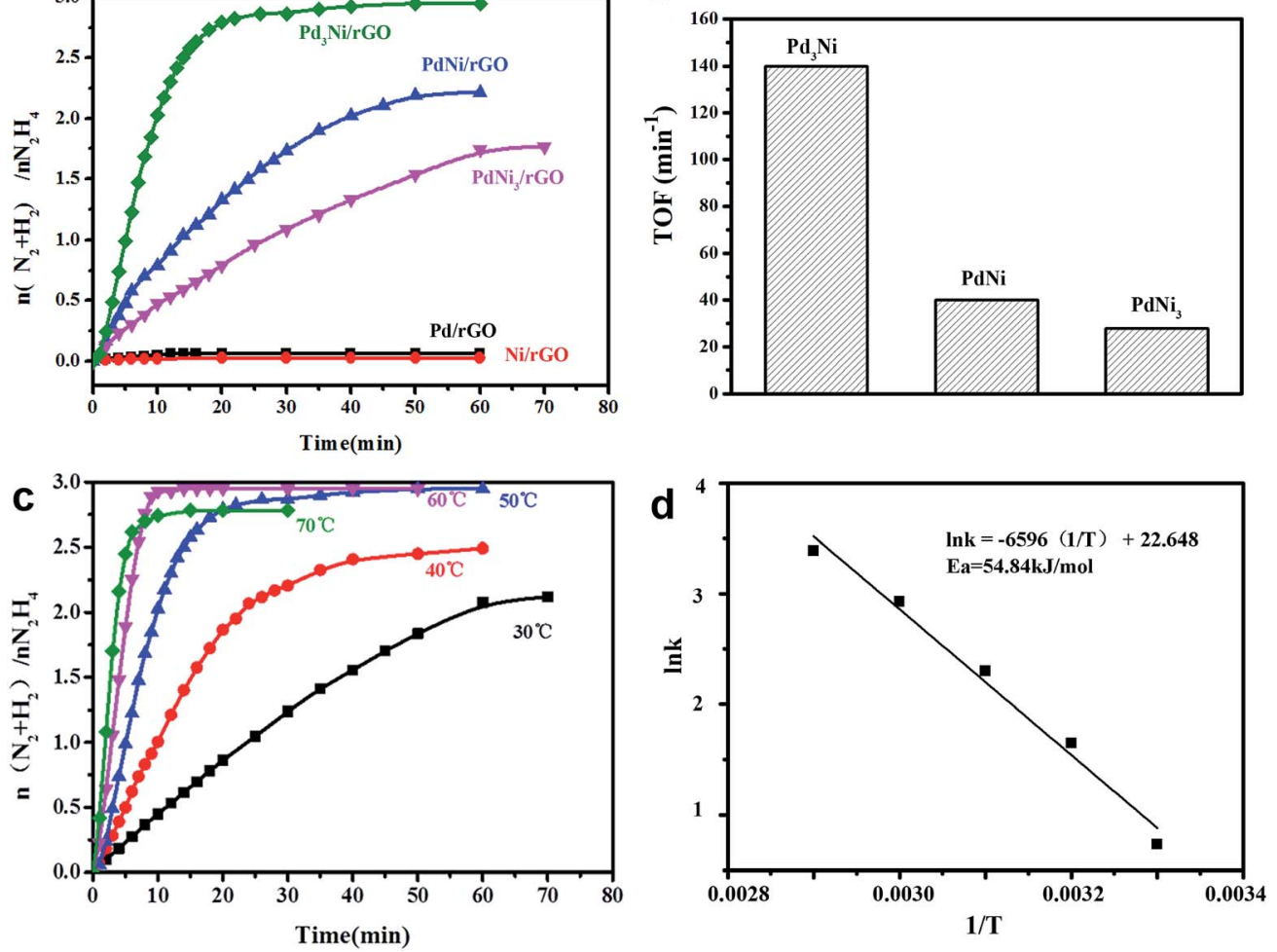

Fig. 5 (a) Time course plots for the decomposition of aqueous solution of hydrazine over $\mathrm{Pd}-\mathrm{Ni} / \mathrm{rGO}$ with $\mathrm{NaOH}(0.5 \mathrm{M})$ at $50{ }^{\circ} \mathrm{C}$ (catalyst $=$ $0.02 \mathrm{~g} ; \mathrm{N}_{2} \mathrm{H}_{4} \cdot \mathrm{H}_{2} \mathrm{O}=2 \mathrm{~mL}$ ). (b) TOF of $\mathrm{Pd}_{3} \mathrm{Ni} / \mathrm{rGO}$, PdNi/rGO and $\mathrm{PdNi}_{3} / \mathrm{rGO}$. (c) Time course plots for hydrogen generation by the decomposition of hydrazine by $\mathrm{Pd}_{3} \mathrm{Ni} / \mathrm{rGO}$ at $30,40,50,60$ and $70{ }^{\circ} \mathrm{C}$. (d) The plot of $\ln k \mathrm{vs} .1 / \mathrm{T}$. 
while monometallic systems, for both $\mathrm{Pd} / \mathrm{rGO}$ and $\mathrm{Ni} / \mathrm{rGO}$, show poor catalytic activities (less than 0.2 equiv. of gas was release). When Pd was alloyed to $\mathrm{Ni}$, the bimetallic system of $\mathrm{PdNi}_{3} / \mathrm{rGO}$ exhibits the activity for the dehydrogenation of hydrazine with the hydrogen selectivity of $54.2 \%$ and the turnover frequency (TOF) value of $27.88 \mathrm{~min}^{-1}$ at $50{ }^{\circ} \mathrm{C}$ (Fig. 5b). The catalytic activity of $\mathrm{PdNi}_{3} / \mathrm{rGO}$ is poor (1.5 equiv. of gas was released over $3 \mathrm{~h}$ ). A higher hydrogen selectivity of $70.7 \%$ and a higher catalytic activity with the TOF value of $40.05 \mathrm{~min}^{-1}$ were observed, when the $\mathrm{Pd}: \mathrm{Ni}$ ratio further increased to $1: 1$. Among all catalysts, $\mathrm{Pd}_{3} \mathrm{Ni} / \mathrm{rGO}$ exhibits the highest catalytic activity with TOF value of $140 \mathrm{~min}^{-1}$ and $100 \%$ hydrogen selectivity, which shows better selectivity than previously reported work. ${ }^{16}$ In order to obtain the activation energy $\left(E_{\mathrm{a}}\right)$ of the dehydrogenation of hydrazine catalysed by $\mathrm{Pd}_{3} \mathrm{Ni} / \mathrm{rGO}$, the catalytic experiments were carried out at temperatures ranging from 30 to $70{ }^{\circ} \mathrm{C}$ (Fig. $5 \mathrm{c}$ and d). The $E_{\mathrm{a}}$ was calculated based on following equation: $E_{\mathrm{a}}=R T \ln A / k$, where $k$ is chemical reaction rate, $T$ is temperature in kelvin, $A$ is pre-exponential factor and $R$ is gas constant. The $E_{\mathrm{a}}$ was determined to be $54.84 \mathrm{~kJ} \mathrm{~mol}^{-1}$, which is close to the reported values. ${ }^{6,16}$ The as-synthesised $\mathrm{Pd}_{3} \mathrm{Ni} / \mathrm{rGO}$ was tested in terms of durability in three cyclic usages (Fig. S4 $\dagger$ ). The loss of activities might be caused by leaching of nanocatalysts, where the loading decrease to $28.3 \%$ after three cycles. The functionalization of rGO with function groups may improve the stability of the catalysts.

The existence of Ni and Pd metals in an alloy state is a key factor behind the observed high catalytic performance. ${ }^{46}$ The monometallic $\mathrm{Pd} / \mathrm{rGO}$ and $\mathrm{Ni} / \mathrm{rGO}$ nanocatalysts show poor catalytic activity for the hydrogen generation from hydrazine, while the presence of both metals with inter-metallic Ni-Pd bonding on the catalyst active centres is vital for the activation of bonds in hydrazine for hydrogen generation. The rGO supports are also important, because they prevent the aggregation of $\mathrm{Pd}_{3} \mathrm{Ni}$ NPs during the dehydrogenation.

\section{Conclusions}

We have developed a composite material of $\mathrm{Pd}-\mathrm{Ni} / \mathrm{rGO}$ as an efficient heterogeneous catalyst for dehydrogenation of hydrazine. The well-dispersed $\mathrm{Pd}-\mathrm{Ni}$ NPs on rGO have been successfully prepared by an in situ reduction of $\mathrm{PdO} / \mathrm{Ni}(\mathrm{OH})_{2}$ on $\mathrm{GO}$, which prevents the further aggregation of $\mathrm{Pd}-\mathrm{Ni}$ NPs during the reduction process. Bimetallic systems (Pd-Ni/rGO) exhibit the high catalytic activity toward dehydrogenation of hydrazine, while the pure metal systems (Pd/rGO and Ni/rGO) show no generation of hydrogen from hydrazine. Among them, $\mathrm{Pd}_{3} \mathrm{Ni}$ / rGO catalyst shows highest catalytic activity and exhibits $100 \%$ hydrogen selectivity. The high activity and selectivity enables $\mathrm{Pd}_{3} \mathrm{Ni} / \mathrm{rGO}$ material as a potential catalyst for practical applications in dehydrogenation of alkaline solution of hydrazine for hydrogen storage in the future.

\section{Acknowledgements}

We thank the financial support from the "Thousand Talents Program" of China, the National Natural Science Foundation of
China (No. 21576006, 21101170, 21573139 and 21601118). We thank Prof. Yu Chen for valuable discussions and comments.

\section{Notes and references}

1 H. B. Gray, Nat. Chem., 2009, $1,7$.

2 C. G. Morales-Guio, L.-A. Stern and X. Hu, Chem. Soc. Rev., 2014, 43, 6555-6569.

3 X. Zou and Y. Zhang, Chem. Soc. Rev., 2015, 44, 5148-5180.

4 S. K. Singh, X.-B. Zhang and Q. Xu, J. Am. Chem. Soc., 2009, 131, 9894-9895.

5 M. Yadav and Q. Xu, Energy Environ. Sci., 2012, 5, 9698-9725.

6 N. Cao, L. Yang, H. Dai, T. Liu, J. Su, X. Wu, W. Luo and G. Cheng, Inorg. Chem., 2014, 53, 10122-10128.

7 S. K. Singh and Q. Xu, J. Am. Chem. Soc., 2009, 131, 1803218033.

8 S. K. Singh, A. K. Singh, K. Aranishi and Q. Xu, J. Am. Chem. Soc., 2011, 133, 19638-19641.

9 L. He, Y. Huang, A. Wang, X. Wang, X. Chen, J. J. Delgado and T. Zhang, Angew. Chem., Int. Ed., 2012, 51, 6191-6194.

10 T. He, H. Wu, G. Wu, J. Wang, W. Zhou, Z. Xiong, J. Chen, T. Zhang and P. Chen, Energy Environ. Sci., 2012, 5, 56865689.

11 Z. Huang and T. Autrey, Energy Environ. Sci., 2012, 5, 92579268.

12 J. Wang, X.-B. Zhang, Z.-L. Wang, L.-M. Wang and Y. Zhang, Energy Environ. Sci., 2012, 5, 6885-6888.

13 L. He, Y. Huang, A. Wang, X. Wang and T. Zhang, AIChE J., 2013, 59, 4297-4302.

14 S. K. Singh and Q. Xu, Chem. Commun., 2010, 46, 6545-6547.

15 S. K. Singh and Q. Xu, Inorg. Chem., 2010, 49, 6148-6152.

16 S. K. Singh, Y. Iizuka and Q. Xu, Int. J. Hydrogen Energy, 2011, 36, 11794-11801.

17 H.-L. Wang, J.-M. Yan, S.-J. Li, X.-W. Zhang and Q. Jiang, J. Mater. Chem. A, 2015, 3, 121-124.

18 Y.-J. Zhong, H.-B. Dai, Y.-Y. Jiang, D.-M. Chen, M. Zhu, L.-X. Sun and P. Wang, J. Power Sources, 2015, 300, 294-300.

19 C. Li, T. Wang, W. Chu, P. Wu and D. G. Tong, Nanoscale, 2016, 8, 7043-7055.

20 G. Yao, F. Chen, Z. Huo and F. Jin, Int. J. Hydrogen Energy, 2016, 41, 9135-9139.

21 X. Miao, M. M. Chen, W. Chu, P. Wu and D. G. Tong, ACS Appl. Mater. Interfaces, 2016, 8, 25268-25278.

22 S. De, J. Zhang, R. Luque and N. Yan, Energy Environ. Sci., 2016, 9, 3314-3347.

23 J. Chen, Q. Yao, J. Zhu, X. Chen and Z.-H. Lu, Int. J. Hydrogen Energy, 2016, 41, 3946-3954.

24 Z. Zhang, Z.-H. Lu and X. Chen, ACS Sustainable Chem. Eng., 2015, 3, 1255-1261.

25 Z. Zhang, Z.-H. Lu, H. Tan, X. Chen and Q. Yao, J. Mater. Chem. A, 2015, 3, 23520-23529.

26 Y. Zhao, X. Yang, J. Tian, F. Wang and L. Zhan, Int. J. Hydrogen Energy, 2010, 35, 3249-3257.

27 W. Gao, C. Li, H. Chen, M. Wu, S. He, M. Wei, D. G. Evans and X. Duan, Green Chem., 2014, 16, 1560-1568.

28 D. Bhattacharjee, K. Mandal and S. Dasgupta, J. Power Sources, 2015, 287, 96-99. 
29 B. Liu, H. Yao, W. Song, L. Jin, I. M. Mosa, J. F. Rusling, S. L. Suib and J. He, J. Am. Chem. Soc., 2016, 138, 4718-4721. 30 L. Bai, X. Wang, Q. Chen, Y. Ye, H. Zheng, J. Guo, Y. Yin and C. Gao, Angew. Chem., 2016, 128, 15885-15890.

31 T. Imaoka, H. Kitazawa, W.-J. Chun and K. Yamamoto, Angew. Chem., Int. Ed., 2015, 54, 9810-9815.

32 H. Wei, X. Liu, A. Wang, L. Zhang, B. Qiao, X. Yang, Y. Huang, S. Miao, J. Liu and T. Zhang, Nat. Commun., 2014, 5, 5634 .

33 A. Corma, P. Concepción, M. Boronat, M. J. Sabater, J. Navas, M. J. Yacaman, E. Larios, A. Posadas, M. A. López-Quintela, D. Buceta, E. Mendoza, G. Guilera and A. Mayoral, Nat. Chem., 2013, 5, 775-781.

34 J. Li, P. Zhou, F. Li, R. Ren, Y. Liu, J. Niu, J. Ma, X. Zhang, M. Tian, J. Jin and J. Ma, J. Mater. Chem. A, 2015, 3, 1126111268.

35 J. Shi, Q. Ji, Z. Liu and Y. Zhang, Adv. Energy Mater., 2016, 6, DOI: $10.1002 /$ aenm.201600459.

36 Q. Yao, Z.-H. Lu, W. Huang, X. Chen and J. Zhu, J. Mater. Chem. A, 2016, 4, 8579-8583.
37 W.-d. Zhong, X.-k. Tian, C. Yang, Z.-x. Zhou, X.-w. Liu and Y. Li, Int. J. Hydrogen Energy, 2016, 41, 15225-15235.

38 Y. Liu, H. Tsunoyama, T. Akita, S. Xie and T. Tsukuda, ACS Catal., 2011, 1, 2-6.

39 Z. Niu and Y. Li, Chem. Mater., 2014, 26, 72-83.

40 M. Cargnello, C. Chen, B. T. Diroll, V. V. T. Doan-Nguyen, R. J. Gorte and C. B. Murray, J. Am. Chem. Soc., 2015, 137, 6906-6911.

41 L. Fumin, G. Xueqing, X. Qi, L. Shuni, C. Yu and L. Jong-Min, Nanotechnology, 2015, 26, 065603.

42 X. Gao, F. Li, Y. Li, S. Li, Y. Chen and J.-M. Lee, J. Power Sources, 2015, 280, 491-498.

43 X. Gao, Y. Li, Q. Zhang, S. Li, Y. Chen and J.-M. Lee, J. Mater. Chem. A, 2015, 3, 12000-12004.

44 A. L. Patterson, Phys. Rev., 1939, 56, 978-982.

45 C. Paduani, J. Magn. Magn. Mater., 2011, 323, 2076-2079.

46 S. N. Oliaee, C. Zhang, S. Y. Hwang, H. M. Cheung and Z. Peng, J. Phys. Chem. C, 2016, 120, 9764-9772. 